\title{
Lúpus Eritematoso Sistêmico Grave Associado à Síndrome da Resposta Inflamatória Sistêmica na Adolescência
}

Correspondence addresses: Dra. Rita Mira de Oliveira rita.mira@santacasaba.org.br

Received: August 2, 2021

Revised: August 22, 2021

Accepted: August 26, 2021

Published: September 30, 2021

Data Availability Statement: All relevant data are within the paper and its Supporting Information files.

Funding: This work was the result of authors' initiative. There was no support of research or publication funds.

Competing interests: The authors have declared that no competing interests exist.

\section{Copyright}

(C) 2021 by Santa Casa de Misericórdia da Bahia. All rights reserved. ISSN: 2526-5563

DOI: 10.35753

\section{Severe Systemic Lupus Erythematosus Associated with Systemic Inflammatory Response Syndrome in Adolescence}

\author{
Rita Mira de Oliveira ${ }^{1 *}$, Angela Vasconcelos ${ }^{1}$, Ramón Nascimento $^{1}$, Fabiana \\ Ribeiro $^{1,2}$, Nara Andrade ${ }^{1,3}$ \\ ${ }^{1}$ Chefe do Serviço de Pediatria Clínica do Hospital Santa Izabel; ${ }^{2}$ Residente de Pediatria \\ do Hospital Geral Roberto Santos; ${ }^{3}$ Residente de Pediatria do Hospital Martagão Gesteira
}

Este estudo apresenta um relato de caso de Lúpus Eritematoso Sistêmico (LES) Grave em um adolescente. $O$ paciente apresentou COVID-19 três meses antes da admissão no Hospital Santa Izabel e apendicectomia há 25 dias da admissão. Foi internado com suspeita de Doença de Kawasaki (DK), entretanto, com os achados em exames complementares positivos para LES, presença da síndrome da resposta inflamatória sistêmica e evolução clínica, o paciente apresentou critérios para diagnóstico de LES

Palavras-Chave: Lúpus Eritematoso Sistêmico; Síndrome da Resposta Inflamatória Sistêmica; Evolução Clínica.

This study presents a case report of Severe Systemic Lupus Erythematosus (SLE) in an adolescent. The patient presented COVID-19 and did an appendectomy three months and 25 days before admission to the Hospital Santa Izabel, respectively. He was admitted with suspicion of Kawasaki Disease (KD). However, with the findings of positive complementary tests for SLE, the presence of systemic inflammatory response syndrome, and clinical evolution, the patient met the criteria for the diagnosis of SLE.

Keywords: Systemic Lupus Erythematosus; Systemic Inflammatory Response Syndrome; Clinical Evolution.

\section{Relato de Caso e Discussão}

Paciente ASCF do sexo masculino, 12 anos, negro, previamente sem comorbidades, compareceu ao ambulatório de pediatria com queixa de rash cutâneo e discreto edema em membros inferiores, o que foi optado inicialmente por conduta expectante. Evoluiu com febre, náuseas, vômitos e piora do edema em membros inferiores e progressão para membros superiores e face, associado ao aparecimento de leões cutâneas difusas no corpo e hiperemia conjuntival, sendo necessário buscar a emergência para avaliação médica.

A história pregressa do paciente consistia em infecção por COVID-19 há 3 meses da admissão e apendicectomia há 25 dias da admissão. Além 
disso, a história familiar do paciente é positiva para lúpus (a irmã é portadora da doença). Ao exame físico, o paciente apresentava estado geral regular, mucosas hipocrômicas 2+/4+, com edema periorbitário em face, membros e parede abdominal. A pele apresentava-se áspera, ressecada, avermelhada com discretas placas hiperemiadas. Presença de lesões xeróticas, com coloração azulada e manchas avermelhadas que clareiam com a digito-pressão. Em orofaringe, foram percebidas lesões aftoides.

O paciente foi internado em unidade hospitalar em 06/05/2021, com suspeita de Doença de Kawasaki (DK) e foi solicitado hemograma,que não apresentava alteração; e ecocardiograma foi realizado em 10/05/2021 para investigação complementar da suspeita diagnóstica. No exame, foi identificado: coronárias normoposicionadas com dilatação do tronco da coronária esquerda (tronco coronária esquerda apresentava paredes mais hiperecogênicas e ectasia, medindo $0,50 \mathrm{~cm}$ $\mathrm{Z}$ score $=+3,81$ - Coronária direita de aspecto normal, medindo $0,27 \mathrm{~cm}$ em óstio $Z$ score: -0,36), caracterizando-se como aneurisma de coronária, fortalecendo a hipótese de DK incompleto. Foi realizado o tratamento com Imunoglobulina humana associada a ácido acetilsalicílico em dose anti-agregante plaquetária. Apresentou persistência da febre e por isso foi realizada nova dose de imunoglobulina após 48h. Suspeitou-se também de síndrome inflamatória multissistêmica pediátrica, pela idade do paciente e por se tratar de uma quadro inflamatório multissistêmico, atingindo o sistema cardiovascular e um histórico de RT-PCR para SARS-CoV-2 em abril de 2021.

Evoluiu no internamento, após as duas doses de imunoglobulina, com melhora da hiperemia conjuntival e edema em face e em parede abdominal, porém mantendo picos febris diários, lesões e rash cutâneo, bem como as lesões aftoides que dificultavam a ingestão de alimentos. Foram realizados novos exames laboratoriais que evidenciaram uma pancitopenia (hemoglobina de $7,8 \mathrm{~g} / \mathrm{dL}$; contagem de leucócitos de $2.140 \mu \mathrm{L}$ e contagem de plaquetas de $136.000 \mathrm{mil}$ ), evento não justificado pela $\mathrm{DK}$.

Diante disso, o Lúpus Eritematoso Sistêmico (LES) se apresentou como suspeita diagnóstica e foram solicitados novos exames para investigação (Tabela 1).

Apresentou sorologias virais não reagentes para os tipos virais mais comuns e em ecocardiograma de seguimento foram visualizados derrames pericárdico e pleural. No mesmo período, foi realizada biópsia de pele que evidenciou um padrão inflamatório nas lesões cutâneas típico de LES. Diante dos achados em exames complementares e evolução clínica, o

Tabela 1. Exames de sangue.

\begin{tabular}{ll}
\hline Exames & Resultado \\
\hline Ferritina & $1.103 \mathrm{ng} / \mathrm{mL}$ \\
LDH & $513 \mathrm{UI} / \mathrm{L}$ \\
Anticoagulante lúpico & 1,08 (não detectado) \\
cardiolipina IgA & Não reagente \\
cardiolipina IgM & Fracamente reagente \\
cardiolipina IgG & Fracamente reagente \\
Coombs direto & Reagente \\
DNA nativo & Não reagente \\
FAN & $\begin{array}{l}\text { Padrãomisto nuclearhomogêneo epontilhado } \\
\text { título 1:80 e 1:320 respectivamente }\end{array}$ \\
\hline ANTI SSB/LA & Não reagente \\
\hline
\end{tabular}


paciente apresentou critérios para diagnóstico de LES. Foi então iniciada prednisona e hidroxicloroquina para tratamento específico.

As hemoculturas colhidas em 15/05/2021 e 17/05/2021 positivaram para $S$. aureus, $K$. pneumoniae e Kluyvera cryocrescens, e iniciada antibioticoterapia com cefepime e oxacilina. Posteriormente a antibioticoterapia foi modificada para cefepime, vancomicina e micafungina por deterioração clínica do paciente.

Diante da persistência da gravidade do quadro e da febre o paciente foi transferido para unidade de terapia intensiva pediátrica (UTIP) para realização de pulsoterapia.

Em UTIP evoluiu com piora do quadro inflamatório sistêmico, com evolução de dispneia, descompensação hemodinâmica e cárdica, sendo necessária intubação orotraqueal, nefrite lúpica e psicose lúpica. Neste momento foi realizada pulsoterapia com metilprednisolona, seguida de ciclofosfamida.

Após pulsoterapia, apresentou melhora clínica, porém com persistência da pancitopenia grave, foram realizados mielograma com biópsia de medula que indicaram possibilidade de síndrome hemofagocitica, por apresentar células hemofagocíticas, desencadeada pelo LES, porém a amostra estava diluída para conclusão diagnóstica.
Durante o internamento foi realizada nova dose de imunoglobulina devido à atividade inflamatória da doença. O paciente evoluiu gradualmente com melhora clínica importante, sendo transferido para enfermaria, onde permaneceu hospitalizado para realização de segunda pulsoterapia com ciclofosfamida um mês após a primeira dose.

Evoluiu no período com remissão do quadro infeccioso, melhora do quadro inflamatório, parâmetros laboratoriais dentro da normalidade, ecocardiograma com diminuição da dilatação de coronárias, com lesões cutâneas em cicatrização. Paciente recebeu alta hospitalar com indicação de realizar pulsoterapia com infusão de ciclofosfamida mensal por 4 meses e acompanhamento com reumatopediatra.

\section{Referências}

1. Machado C, Ruperto N. Consenso em reumatologia pediátrica: parte II - definição de melhora clínica para o lúpus eritematoso sistêmico e dermatomiosite juvenil. Revista Brasileira de Reumatologia [online]. 2005 , v. 45.

2. Silva CA. Childhood-onset systemic lupus erythematosus: early disease manifestations that the paediatrician must know. Expert Rev Clin Immunol. 2016;12:907-10. 